\title{
Fast charging systems for supercapacitors - circuit solutions and comparative study
}

\author{
A. $\mathrm{Muc}^{1}, \mathrm{~J}$. Iwaszkiewicz ${ }^{1}$ \\ ${ }^{1}$ Department of Electrical Engineering \\ Gdynia Maritime University, Poland \\ Morska St. 81-87 (Poland) \\ e-mail: j.iwaszkiewicz@we.umg.edu.pl, a.muc@we.umg.edu.pl
}

\begin{abstract}
The article discusses fast-charging systems for supercapacitors as promising power storages. Analyses of constant voltage charging systems, constant current systems and constant power systems have been conducted. Selected network solutions and controlling algorithms were compared based upon performed simulations results. The mutual impact between electrical transformers utilized in the charging process has been taken into consideration. The higher THD factor has been selected as the criterion. A short comparison of few autonomous power storages has been presented, namely supercapacitor's, flywheel's and fuel cell's. To the needs of the research, the mapping of currents and voltage in the supercapacitor, in the proxy circuit as well as in the electrical network has been registered. The impact of the entire charging system on the electrical network has been evaluated and calculated according to the harmonic THD factor.
\end{abstract}

Key words: charging, supercapacitors, power

\section{Introduction}

The need for utilizing power storages in electrical networks arises from several reasons. The issue of power continuity maintenance, when the power is produced by renewable resources, is one of the premises. Concurrently, in the maritime industry, when electrical drives are used there are problems with voltage dips and fluctuation when electric motors start because of stepped great power requirement. Power supply maintenance is another but very important case. The problem especially includes hospitals, governmental entities and any other place or institution where power failure can pose a threat to the human life. Another necessity of energy storage relates to power recovery systems, e. g. braking in electrical vehicles, elevators and others [1]. In all of these cases and many others, manufacturers use various methods to keep the electrical energy stability. As energy storages they use different storage types: chemical, mechanical, kinetic, electrical. It is worth noting here that every power fluctuation generates losses. Considering the argumentation, a natural solution and compromise between profitability and efficiency is a power storage.

Modern electrical networks could not exist without various forms of power storing that can be integrated on different levels of the power engineering chain. Power storages are applied as reserve energy sources, elements of voltage and frequency control, cost management units as well as capacity shaping and flattening devices in industry. In terms of simplicity and safety, they can be used in households, medium-sized and large commercial as well as in industrial companies. Apart from the expected application in transportation in the upcoming years, fuel cells and flow accumulators have the potential to be used in stationary solutions. The most common form of storing energy on a large scale are pumped hydroelectric energy storages, whereas accumulators, flywheels and supercapacitors are put to use in low power networks. Every technology has its advantages and disadvantages; utilization depends on the application and developmental research [2].

At present, electrical energy sourcing is as serious problem as its efficient distribution, storing and processing, because of the massive losses each operation might generate. Charging the capacitor by placing opposite electric charges on the sides is a solution of storing electrical energy that has been used since the first modern electricity experiments. Capacitors have been commonly used in electronics and electrical engineering and, simultaneously, their constant construction development and manufacturing methods followed [3].

The first supercapacitors for sale were released by Panasonic under the name "GoldCap". Currently, supercapacitors are also being produced by the following companies: EPCOS, AMS Electronic, Nec, Maxwell, Tokin, Kanebo, Elna. One of the biggest achievements of modern technology is the invention of materials, which have been used in the constructing of supercapacitors also called ultracapacitors or two-layer capacitors. Due to the application of new materials a large, efficient electrode space with small gaps has been invented. Supercapacitors with quick charging systems may be an alternative to voltaic batteries as autonomous electrical energy storages since they are superior in terms of charging speed, lifespan and generated impulse power. Research and works dedicated to supercapacitors contribute larger capacities retaining the principal advantages. Supercapacitors can be placed among traditional capacitors and accumulators for they represent the qualities of both. Not only can a supercapacitor accumulate vast amounts of electrical energy (though a segment lower), but also absorb and deliver big power values [4]. 


\section{Autonomous power storages}

Considering power storing, two key parameters have a fundamental meaning: energy density and power density. The first parameter defines the amount of energy which can be stored in a provided volume. The density of power defines the mode in which energy can be stored in a device. The higher the value, the shorter the time of charging and discharging. The ideal energy storage device should offer high energy density levels and high-power density levels. There are three types of autonomous electrical energy storage devices: electrical accumulators, flywheels and capacitors or their modified version, also known as supercapacitors. Table 1 presents a juxtaposition of the most important features of selected energy storages. Table 2 presents averaged parameters of selected electrical energy storages.

Table 1. Advantages and disadvantages of selected energy storages

\begin{tabular}{|c|c|c|}
\hline $\begin{array}{l}\text { Energy } \\
\text { storage }\end{array}$ & Advantages & Disadvantages \\
\hline $\begin{array}{l}\text { Supercapacit } \\
\text { ors }\end{array}$ & $\begin{array}{l}\text { - The highest impulse power among the listed devices } \\
\text { - } \quad \text { Control of stored energy } \\
\text { - } \quad \text { Ease in exploitation } \\
\text { - High charging speed } \\
\text { - Long life span of the device (approximately one } \\
\text { million charging/discharging cycles) }\end{array}$ & $\begin{array}{l}\text { - The lowest energy density among all listed } \\
\text { devices } \\
\text { - Subject to quick self-discharging in } \\
\text { comparison with accumulators } \\
\text { - Variable voltage value in supercapacitor's } \\
\text { clamps }\end{array}$ \\
\hline Flywheels & $\begin{array}{ll} & \text { Relatively high energy density } \\
\text { - } & \text { High power output } \\
& \text { Control of accumulated energy } \\
\end{array}$ & $\begin{array}{ll} & \text { High price of the device } \\
- & \text { Problematic exploitation }\end{array}$ \\
\hline $\begin{array}{l}\text { Electro- } \\
\text { chemical } \\
\text { accumulators }\end{array}$ & $\begin{array}{l}\text { - } \quad \text { High electrical energy density } \\
\text { - The most common form of electrical energy storage } \\
\text { - low prices } \\
\text { - Low self-discharging }\end{array}$ & $\begin{array}{ll}\text { - } & \text { Low impulse power } \\
\text { - } & \text { Lack of control over stored electrical energy } \\
\text { - } & \text { Harmful to the environment when reprocessed } \\
\text { - } & \text { Problematic exploitation } \\
\text { - } & \text { Short device life span } \\
\text { - } & \text { Susceptible to complete discharging } \\
\end{array}$ \\
\hline Fuel cells & $\begin{array}{l}\text { - The highest electrical energy density } \\
\text { - } \quad \text { Low exploitation costs } \\
\text { - The possibility of generating sustained electrical } \\
\text { energy streams without charging } \\
\text { - High reliability } \\
\text { - An ecological energy production process } \\
\text { An easy and economical construction of the device }\end{array}$ & $\begin{array}{l}\text { - } \\
\text { - } \quad \text { Lelatively low power } \\
\text { - } \quad \text { Expensive materials for catalyzers and a costly } \\
\text { process of extracting hydrogen }\end{array}$ \\
\hline
\end{tabular}

Referring to the information in Table 1 and scientific research, one can risk the statement that the most developmental type of energy storage in the nearest future will be supercapacitors [5]. In mathematical descriptions, supercapacitors can be treated as a hybrid of classical electro-chemical cells and traditional capacitors. Low working voltage at around $3 \mathrm{~V}$ is a characteristic trait, which is the reason for building so called 'modules' serially connected bigger structures in supercapacitors. In order to control the working parameters, voltage and temperature control systems are installed which is caused by a high capacity tolerance $( \pm 20 \%)$ and unequal distribution. The most frequently presented mathematical model of the supercapacitor is the one of an electrical circuit composed of RLC (resistor inductor capacitor) elements.

In contributions [6] the supercapacitor models are presented as a serially connected resistor with a linear or solid capacitor. A first-degree model with a variable capacity value (Fig. 1) has been used to present the supercapacitor's module.

The parallel connection of two capacitors displayed on the scheme of the supercapacitor's model with $\mathrm{ku}_{\mathrm{SC}}$ and $\mathrm{C}_{\mathrm{SC} 0}$ is a fundamental part of the circuit reflecting the capacity value of the supercapacitor which changes depending on the network voltage. The inner dropping resistance $R_{E S R}$ models the losses of energy, which is generated by the flowing current $i_{S C}$ during charging. The connection between linings and entry clamps is shown with inductance L. The losses of energy during self-discharging are represented by the parallel resistance $R_{E P R}$.

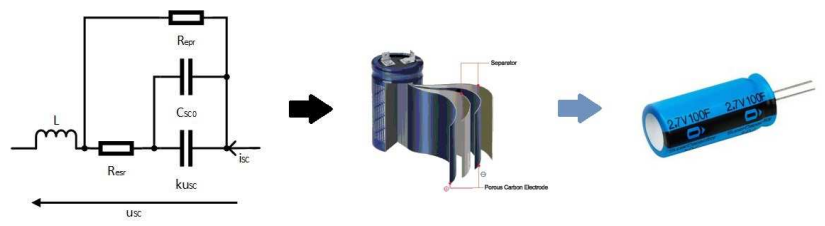

Fig. 1. The supercapacitor model with a first-degree capacity variable [7].

The mathematical description of the supercapacitor can be presented in capacity equations, voltage and serial as well as parallel resistance. It has been presented in action [7-8]. The capacity of the supercapacitor $\mathrm{C}_{\mathrm{SC}}$ presents the equation (1), where $\mathrm{u}_{\mathrm{SC}}-$ the voltage on the supercapacitor clamps, $\mathrm{C}_{\mathrm{SC} 0}-$ the capacity of the supercapacitor at voltage $0 \mathrm{~V}$, ak - the quotient describing the relation between the supercapacitor's voltage and capacity.

$$
C_{S C}\left(u_{S C}\right)=C_{S C 0}+k u_{S C}
$$

Voltage of the supercapacitor $\mathrm{u}_{\mathrm{SC}}$ is expressed by equation (2), where: $I_{S C}$ - constant current of charging the 
supercapacitor, $\mathrm{t}$ - charging time of the supercapacitor, $\mathrm{u}_{\mathrm{SC} 0}$ - initial voltage of the supercapacitor.

$$
u_{S C}(t)=-\frac{C_{S C 0}}{k}+\frac{\sqrt{2 k I_{S C} t+\left(C_{S C 0}+k u_{S C 0}\right)^{2}}}{k}
$$

The resistances picturing losses have been expressed by correlations (3) and (4). The series resistance $R_{E S R}$ with losses at charging time is represented by equation (3), where: - voltage decrease in charging the supercapacitor, constant current while charging the supercapacitor in time [9].

$$
R_{E S R}=\frac{\Delta u_{S C}}{\Delta i_{S C}}
$$

Parallel resistance $R_{E P R}$ has been described with equation (4), where: - voltage decrease in charging the supercapacitor, - initial voltage of the supercapacitor, - capacity of the supercapacitor [9].

$$
u_{S C}(\mathrm{t})=u_{S C 0} e^{\frac{t}{R_{E P R} C_{S C}}}
$$

\section{Network solutions}

In electrical energy storage systems there is the need for quick energy storing, which later is used to power receivers. The application of dedicated charging solutions in supercapacitors is a necessary requirement in such cases. Generally, three basic charging solutions can be distinguished: constant current charging, constant voltage charging and constant power charging. The constant voltage system generates several issues, the one being a discharged supercapacitor with its low internal resistance connected to such an energy source and, as a result, creating a short-circuit. The initial current pursues infinity, because it is limited only by the wires' resistance and the source's efficiency. During simulations, charging a set of supercapacitors with a capacity of several farads to a voltage level of $100 \mathrm{~V}$ might last less than several fractions of a second, though the initial current reaches tens of thousands of amperes. For this reason, a practical application of such a system is not justified.

Subsequent solutions rely on systems with current charging limitations. Charging with constant current or constant power except for the more beneficial technical realization, also carries economic gains. Depending on the requirements, charging can last long or be quick. Figure 2 presents the comparison of constant current charging with constant power charging characteristics.

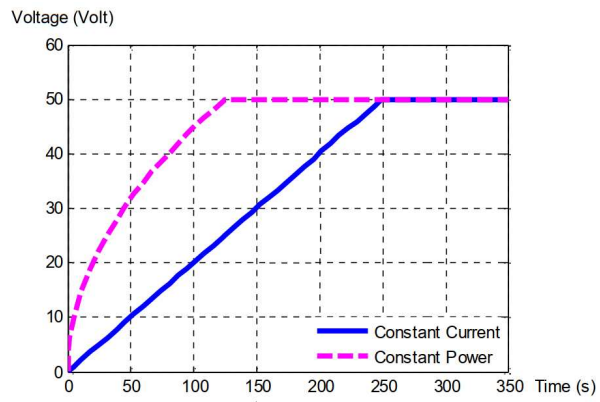

Fig. 2. Comparison of charging with constant current and constant voltage in time.

Figure 3 depicts systems which include both methods of supercapacitor charging. a)

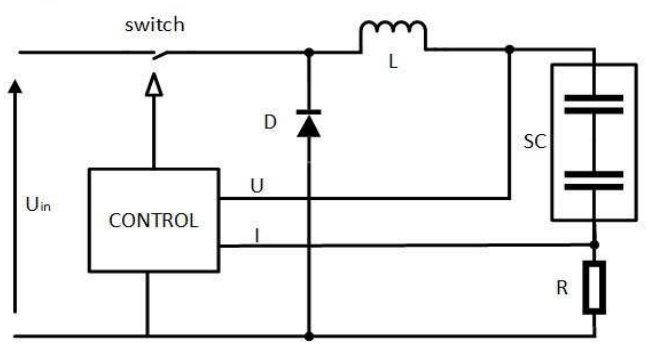

b)

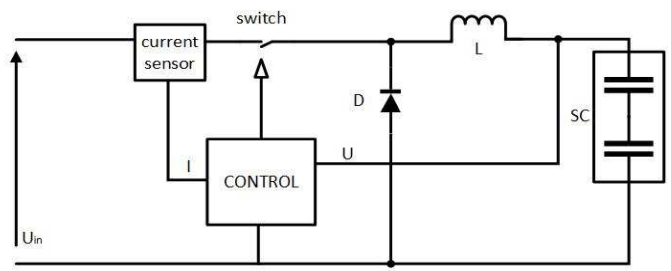

Fig. 3. Scheme of charging with constant current (a) or constant power (b).

The presented topologies rest upon a simple DC/DC converter which is identified in the power electronics literature as the impulse power supply unit decreasing Buck type voltage [8]. The application of constant power charging should result in faster energy storing in the accumulator, which is a consequence of the characteristic shown in Figure 2. Figure 4 shows the algorithm and the constant current charging scheme, where a rectifier has been used as an AC/DC converter [10,11]. Figure 5 represents the algorithm and the constant power charging system, where a rectifier has also been used as an AC/DC converter.

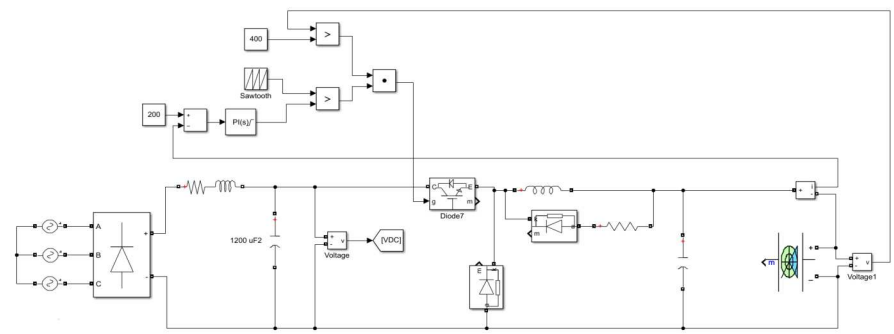

Fig. 4. Scheme of algorithm and constant current charging designed in Matlab.

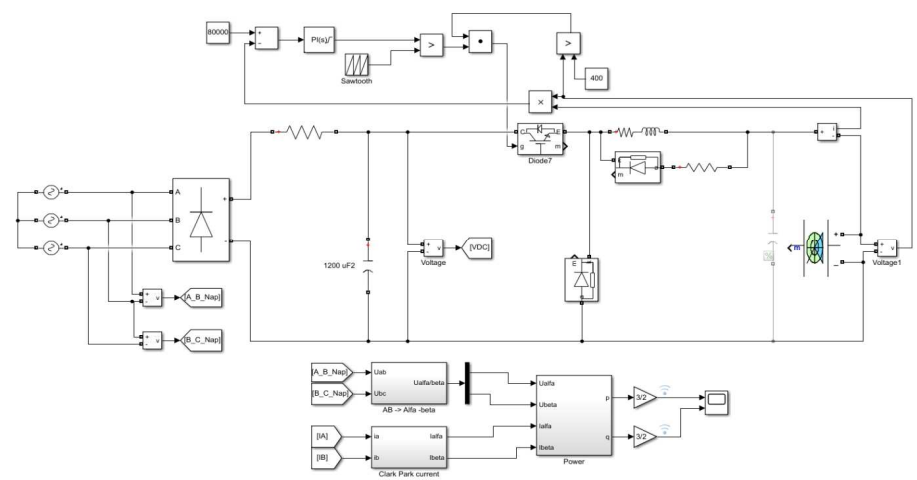

Fig. 5. Scheme of algorithm and constant power charging designed in Matlab.

After counting the characteristics of every charging method, schemes presented in Figure 3 and algorithms 
included in Figures 4 and 5, simulative research has been done in reference to the electrical network according to the scheme in Figure 6.

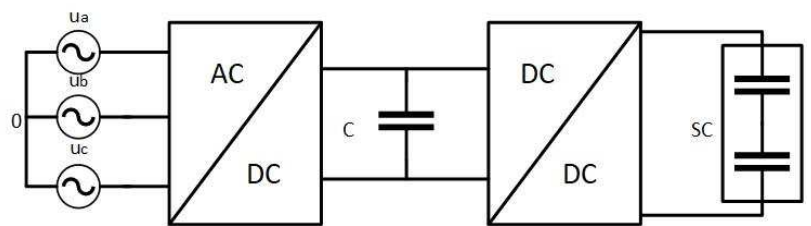

Fig. 6. Charging system with constant current or constant power from a 3-phase network.

In the conducted simulative research, the system of the AC/DC converter operating as a 3-phase rectifier as well as the network synchronized inverter have been discussed. Each of these solutions allows to obtain different charging parameters of supercapacitor packages. At the beginning of the network a 3-phase alternative current power source of a $3 \times 400 \mathrm{~V}$ voltage is placed, sequentially: the diode rectifier scheme or the network synchronized inverter, the filter and the scheme that changes the constant current parameters in the form of an impulse transverter. In accordance with the applied charging method, the DC/DC converted is steered so that it can maintain the constant current or constant power of the network that is charging the supercapacitor's battery. Figures 4 and 5 do not show the utilized network choking coils, which have been placed between the 3-phase alternative current power sources and the AC/DC converter.

\section{Simulative research}

The aim of the simulative research is to compare the previously described DC/DC converter steering algorithms which are directly responsible for the supercapacitors' charging. Additionally, analyzing the cooperation between the DC/DC transverter and the other converters is the extra aim. These converters are responsible for delivering the constant current from the network. Moreover, researching the impact of converters on the power electrics network which charge the supercapacitors is the next objective. The flow of currents and voltages in the supercapacitor, in the intermediary circuit and the power electric network have been registered and monitored in the research. The impact of the entire supercapacitor charging system on the power electric network has been assessed by calculating the THD factor. Simulations have been done with the usage of systems presented in Figures 4 and 5. In these systems a rectifier has been used in the role of an AC/DC converter. Afterwards, the experiment was repeated using the network synchronized inverter.

The scheme with the rectifier from Figure 4 has been used in the first phase of research. In this variant, the function of the DC/DC converter is to maintain the charging current at a constant level of $200 \mathrm{~A}$. Charging a $10 \mathrm{~F}$ supercapacitor to $400 \mathrm{~V}$ lasted 19.9 [s]. The maintained current in the provided scope forced a linear voltage increase in the supercapacitor (Fig. 7). The descending voltage level in the intermediary circuit (Fig. 8) results from the increasing power intake by the charging system. Once charging finishes, voltage rapidly increases.

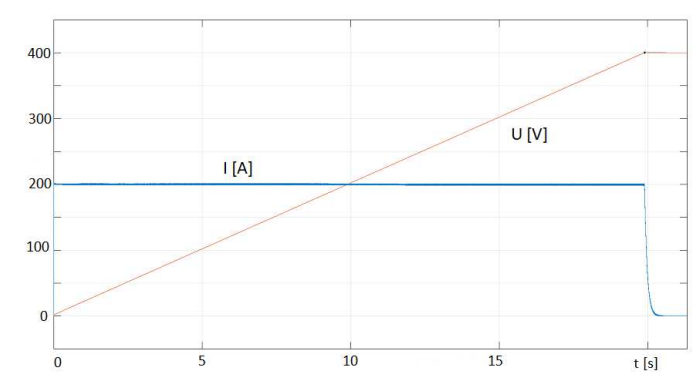

Fig. 7. Charging current (I) and supercapacitor voltage (U).

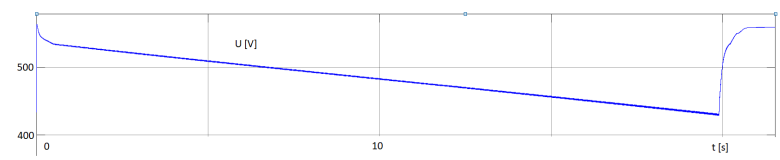

Fig. 8. Voltage of the intermediary circuit (U).

Figure 9 depicts the impact of the charging system on the electrical network model.

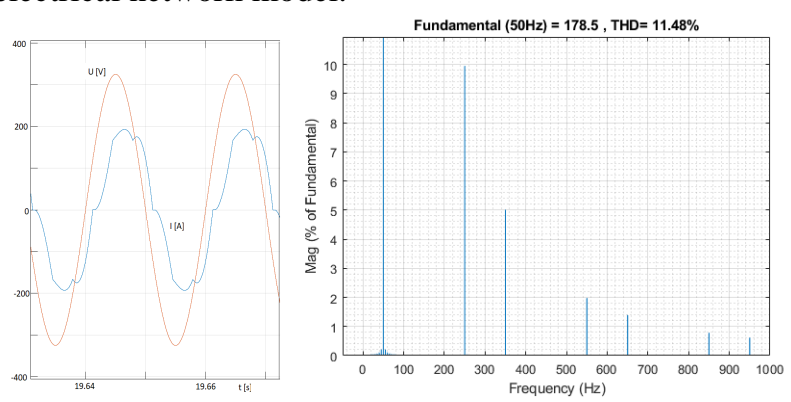

Fig. 9. Current (I) and network voltage (U) for the first phase and the current spectrum and THD value in the final charging phase totaled $11.48 \%$.

Even though a set of chokes positioned before the rectifier has been used, the current distortion reached a high $\mathrm{THD}_{\mathrm{I}}$ value, which totaled about $11.48 \%$ in the final charging phase (Fig. 9).

The negative impact of the presented supercapacitor charging system especially concerns the distortions in the current, whose spectrum is portrayed in Figure 9.

The fifth harmonic amounted $10 \%$, whereas the seventh totaled $5 \%$ of the initial harmonic value. The next phase of research was conducted in the system pictured in Figure 5, where a rectifier for charging the intermediary circuit has also been utilized. Such a circuit charges the $10 \mathrm{~F}$ supercapacitor to $400 \mathrm{~V}$ in 11.74 [s]. The charging power is set to $80 \mathrm{~kW}$.

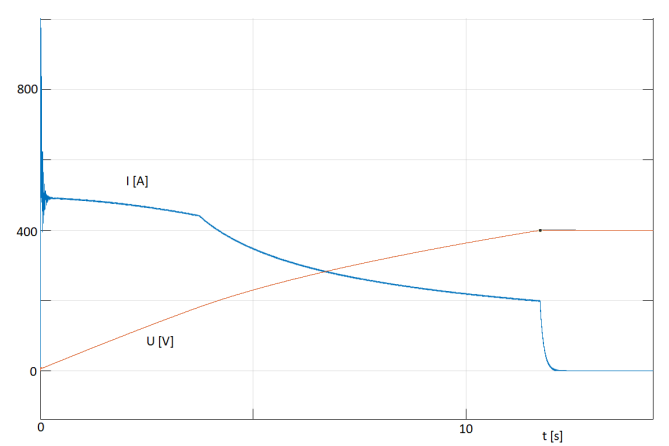

Fig 10. Charging current (I) and supercapacitor voltage (U).

In the beginning phase of charging, an enormous intake of current is observed which balances low voltage. This 
effect is visible in the voltages' course (Fig. 10) as well as in the power characteristics (Fig. 11).

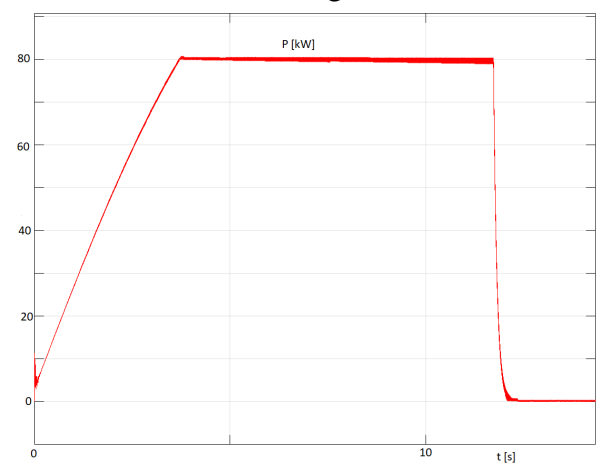

Fig. 11. Charging circuit power (P).

Contrary to the previous circuit and the voltages' course in the intermediary circuit (Fig. 8), sharp voltage increases have been observed (Fig. 12) where the first phase is decisive. At this stage voltage increases similarly to power (Fig. 11).

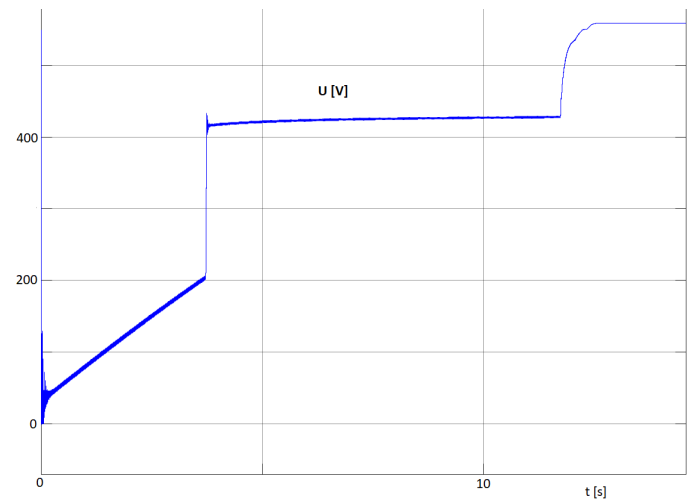

Fig. 12. Intermediary circuit voltage (U).

The impact of the system on the power electrics network is smaller. The calculated $\mathrm{THD}_{\mathrm{I}}$ factor in Figure 13 confirm the above statement.

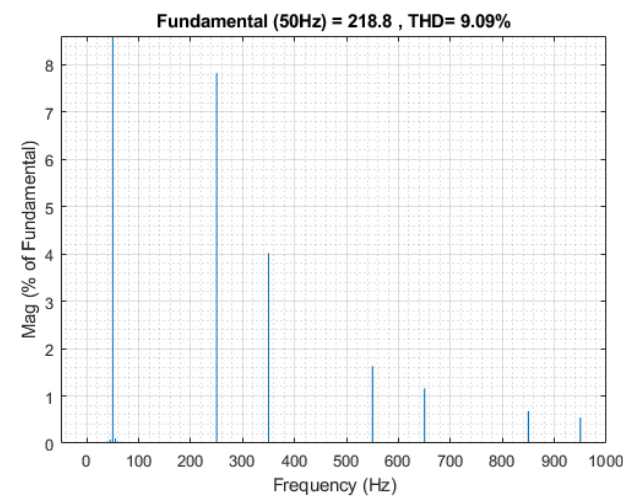

Fig. 13. Current spectrum and $\mathrm{THD}_{\mathrm{I}}$ in the final charging stage.

In these circumstances, the fifth harmonic amounts to less than $8 \%$ and the seventh harmonic to $4 \%$ of the initial harmonic value. THD I quotient value totals $9.09 \%$.

The charging system in further experiments is powered by a network-synchronized converter, which functions as the constant voltage source for the DC/DC converter. The constant voltage amounted 500 VDC in the research. The scheme of the network-synchronized converter consists of a PLL (Phase Look Loop) tracking system and a current comparing system, whose task is to generate the PWM (Pulse Width Modulation) signal to control the inverter keys. Systems equipped in such inverters are frequently applied in electrical drives. They permit to introduce relevant phase shifting which allows to influence the reactive power in the system. The next element is the block that changes electric energy parameters and is able to charge the supercapacitor. There is the possibility of applying charging currents and setting voltages where charging is complete. In this case, the current has been set to $200 \mathrm{~A}$ and voltage has been set to $400 \mathrm{~V}$.

Application of the network-synchronized converter with the constant current charging system enabled the charging of an empty $10 \mathrm{~F}$ supercapacitor in $19.9 \mathrm{~s}$. Voltage and currents in the circuit with the supercapacitor replicate the ones in Figure 7 - in the experiment with the rectifier. The circuit maintained constant current levels at $200 \mathrm{~A}$ which resulted in a linear voltage increase of the charged supercapacitor set. It is worth noting that the voltage flow in the intermediary circuit is virtually constant throughout the entire range.

Constant voltage levels at $500 \mathrm{~V}$ are ensured by the inverter. The increase in voltage when charging is finished results from the inductance in the system and the voltage regulator time constants of this circuit. The voltage is rising due to increasing demand for power. The absorbed current from the network is very close to an ideal agreement with voltage phase $\cos \varphi \approx 1$. Figure 14 shows the source's first stage. Altering the regulator's settings and the inductance value can have an impact on the reactive power value.

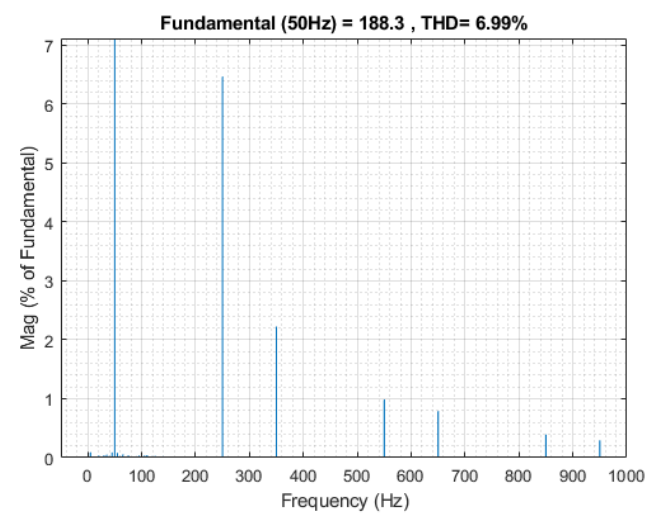

Fig. 14. THD value for the current in the final stage of charging.

Similarly, to the diode rectifier system, simulative research has been conducted for the constant power charging system. Charging power has also been set to 80 $\mathrm{kW}$. The $10 \mathrm{~F}$ supercapacitor was charged to $400 \mathrm{~V}$ in $11.64 \mathrm{~s}$. The voltage in the intermediary circuit (Fig. 15) and the waveforms of the network voltage and current deserves special attention.

The impact of the last supercapacitor charging system on the network is evaluated by the $\mathrm{THD}_{\mathrm{I}}$ factor which totaled $6.99 \%$. In contrast with the previously analyzed systems it emerged that the value of the factor is the lowest, because the charging system, to a lesser degree, caused the network's current distortion. The fifth harmonic did not exceed $6.5 \%$ and the seventh $2.5 \%$ of the initial harmonic value. 


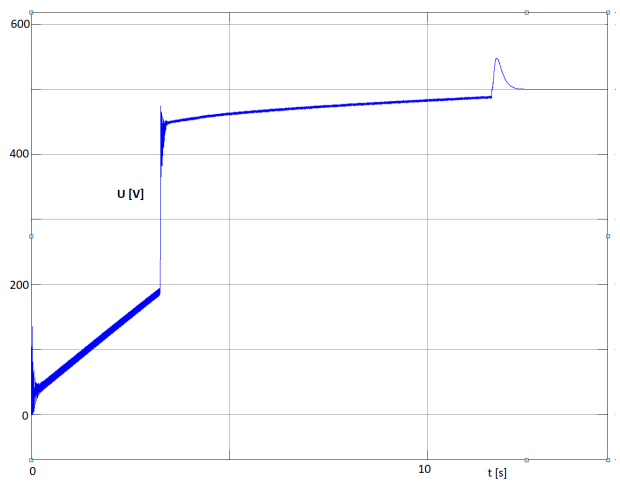

Fig. 15. Intermediary circuit voltage (U).

\section{Conclusion}

Energy storages constructed from supercapacitors enable quick energy accumulation and emission. In addition, the higher number of working cycles supports the more frequent application of supercapacitors instead of accumulators. Energy recovery systems in braking circuits of electric and hybrid cars, braking circuits in elevators, energy storage systems in electric networks and emergency power supply systems are just a few examples where frequent charging and discharging is necessary.

The discussed charging systems show that the process of charging has an impact not only on the charging method, but also on the converter AC/DC circuit in the first degree, whose task is to deliver constant current. Two solutions to AC/DC converters have been discussed: the first being a traditional and simple construction, namely a 3-phase rectifier, and the second being a more elaborate and developed one, namely the network-synchronized inverter. In the article research for the methods of constant current and constant power charging have been presented. After testing the constant voltage charging method it emerged that it is quick, yet possesses a number of issues and disadvantages, such as: an abrupt current increase, excessive overload of the rectifier and network, etc. This issue can be solved by implementing intermediate means which accumulate energy in a long-time span and, in the next step, quickly discards the accumulated energy.

The next stages of the research analyzed the charging circuits, which were powered by a 3-phase source at an effective phase-to-phase voltage of $400 \mathrm{~V}$. Circuits based on the diode rectifier charging with constant current or constant power presented, at the simulation stage, the lowest production costs of such a charger in reality. They charge $10 \mathrm{~F}$ sets to $400 \mathrm{~V}$ in, respectively, $19.9 \mathrm{~s}$ and 11.74 $\mathrm{s}$. The constant power circuit is quicker, generating fewer network current distortions.

Charging of the supercapacitors while using the networksynchronized inverter introduces a number of possibilities in contrast to the diode rectifier. Such a circuit will find its application in solutions where not only quick charging of supercapacitors is vital, but also their discharging - the emission of energy into the network. By means of DC/DC charging systems the network-synchronized inverter the charging of a $10 \mathrm{~F}$ supercapacitor to $400 \mathrm{~V}$ has been simulated. The first system achieved a $19.9 \mathrm{~s}$ time at a $12.33 \%$ network current THD value. The second system, which steered the DC/DC converter to maintain constant charging power, charged the set in $11.64 \mathrm{~s}$ at a $6.99 \%$ network current THD value.

Supercapacitors linked with efficient quick-charging systems seem to be a promising energy storage unit. The rising number of the application of supercapacitors is gaining importance, especially in the context of modernizing and building new electrical infrastructures which will be able to service dispersed systems relying on renewable energy resources. It remains to be seen whether the infrastructure will keep up with the development of the electrical cars industry, which requirements pose a serious challenge for the present electrical power network.

\section{References}

[1] S. Murthy, D. P. Magee and D. G. Taylor, "Vehicle braking strategies based on regenerative braking boundaries of electric machines", Transportation Electrification Conference and Expo (ITEC), 2015 IEEE, Dearborn, MI, 2015, pp. 1-6. doi: 10.1109/ITEC.2015.7165809

[2] F. Naseri; E. Farjah; T. Ghanbari, "An Efficient Regenerative Braking System Based on Battery/Supercapacitor for Electric, Hybrid and Plug-In Hybrid Electric Vehicles with BLDC Motor," in IEEE Transactions on Vehicular Technology, vol.PP, no.99, pp.1-1 doi: 10.1109/TVT.2016.2611655

[3] V. I. Herrera, H. Gaztanaga, A. Milo, A. S. de Ibarra, I. Etxeberria-Otadui, and T. Nieva, "Optimal energy management and sizing of a battery-supercapacitor-based light rail vehicle with a multiobjective approach," IEEE Transactions on Industry Applications, vol. 52, no. 4, pp. 3367-3377, 2016.

[4] S. Kim and P. H. Chou, "Size and topology optimization for superca-pacitor based subwatt energy harvesters," IEEE Transactions on Power Electronics, vol. 28, no. 4, pp. 2068-2080, 2013.

[5] M. Abdou Tankari; G. Lefebvre; K. Bellache; M. Bailo Camara; B. Dakyo, "Supercapacitor lifetime estimation based on Rainflow Cycle Counting Method", IEEE Vehicle Power and Propulsion Conference (VPPC), pp. 1- 6, December 2015

[6] H. Yang and Y. Zhang, "Characterization of supercapacitor models for analyzing supercapacitors connected to constant power elements," Journal of Power Sources, vol. 312, pp. 165-171, 2016.

[7] R. Faranda, M. Gallina, D.T. Son, "A new simplified model of Double-Layer Capa-citors". In Proceedings of International Conference on Clean Electrical Power, 2007, p. $706-710$

[8] V. Musolino, L. Piegari, and E. Tironi, "New FullFrequency-Range Supercapacitor Model with Easy Identification Procedure", IEEE TRANSACTIONS ON INDUSTRIAL ELECTRONICS, VOL. 60, NO. 1, JANUARY 2013.

[9] K. Bellache; M.B. Camara; B. Dakyo, "Hybrid Electric Boat based on variable speed Diesel Generator and lithiumbattery - using frequency approach for energy management", IEEE ACEMP-OPTTMELECTROMOTTON, pp. 744 - 749, Year 2015.

[10] O. Kwon, et al., "Bidirectional Grid-connected Singlepower-conversion Converter with Low Input Battery Voltage," IEEE Industrial Electronics Society, September 2017. DOI: 10.1109/TIE.2017.2752127

[11] G-C. Catalina, V.I. Enric, and J. Calvente, "Design of a Bidirectional DC/DC Converter with Coupled Inductor for an Electric Vehicle Application," Proc. of IEEE 26th Int. Symp. on Industrial Electronics, pp. 688-693, August 2017. 